\title{
Why is Friday better than Sunday? The joy of anticipation hypothesis beats the fundamental law of psychophysics
}

\author{
Sergio Da Silva ${ }^{\text {abc*, }}$, Raul Matsushita ${ }^{\text {def }}$, Eduarda Korzenowski ${ }^{\text {b }}$ \\ ${ }^{a}$ Department of Economics, Federal University of Santa Catarina, 88049-970, Florianopolis S.C., Brazil \\ ${ }^{\mathrm{b}}$ Graduate Program in Economics, Federal University of Santa Catarina, 88049-970, Florianopolis S.C., \\ Brazil \\ ${ }^{\mathrm{c}}$ Graduate Program in Economics, Federal University of Espirito Santo, 29075-910, Vitoria E.S., Brazil \\ ${ }^{\mathrm{d}}$ Department of Statistics, University of Brasilia, 70910-900, Brasilia, D.F., Brazil \\ ${ }^{\mathrm{e}}$ Graduate Program in Statistics, University of Brasilia, 70910-900, Brasilia D.F., Brazil \\ ${ }^{\mathrm{f}}$ Graduate Program in Business Administration, University of Brasilia, 70910-900, Brasilia D.F., Brazil \\ * Corresponding author. Email: professorsergiodasilva@gmail.com
}

ORCID: SDS, 0000-0002-7987-4098; RM, 0000-0001-8864-6356.

\begin{abstract}
We present survey evidence that most people prefer Friday to Sunday. Moreover, we pit against one another two explanations for this fact, the joy of anticipation hypothesis and the Weber law. According to the joy of anticipation hypothesis, Friday promises a weekend ahead, and Sunday does not. The Weber law predicts a relative decrease in the perception of interesting new events as the weekend passes, contributing to the impression that time wanes as Sunday comes. Our findings favor the joy of anticipation hypothesis.
\end{abstract}

JEL classification: D91, D15

Keywords

The joy of anticipation hypothesis; Weber law; fundamental law of psychophysics; Negative temporal preference; Utility of anticipation.

Data accessibility

https://doi.org/10.6084/m9.figshare.18118613.v1

Financial support

Financial support from CNPq, Capes, and FAP-DF is acknowledged.

Disclosure statement

The authors declare no competing interests.

\section{Introduction}

When we ask most people to rank the days of the week in order of preference, they rank Friday higher than Sunday (Farber, 1953). This answer is intriguing because Friday is a workday, and Sunday is not. It is not because people prefer working to relaxing because Saturday is not a workday, and they rank it above both Friday and Sunday. A possible reason is that Friday brings the promise of a weekend ahead. Sunday does not carry with it the joy of anticipation. Expecting a good thing can be more pleasurable than actually experiencing it. Following Sharot (2011), we call this the joy of anticipation hypothesis.

This hypothesis draws on Loewenstein (1987), who considers a similar situation. He asked undergraduates how much they would pay to receive a kiss from a celebrity of their choice. On average, they spent more to receive it in a year than receiving it immediately. One quick kiss leaves no time for anticipation, and the participants would give up the thrill of the wait, the pleasure derived from imagining the expected kiss and perhaps considering how and where it would take place. The students decided to wait for a rewarding event rather than receiving it straight away, suggesting they derived pleasure 
from contemplating something that might happen later. This circumstance means there is a utility of anticipation. Moreover, winning a kiss and postponing receipt showed a negative temporal preference: the students preferred the future to the present.

However, a negative time preference is not only explained by the joy of anticipation. Instead, it can be an illusion created by a desensitized perception in the frame sequence of events. This alternative explanation follows the fundamental law of psychophysics - the Weber law. Loewenstein himself acknowledges this possibility, as he writes: "sequences of outcomes that decline in value are greatly disliked," and "the integral sequence frame, by fusing events into a coherent sequence, promotes concern for the future, thereby creating an appearance of negative time preference" (Loewenstein and Prelec, 1991). So, it is reasonable to inquire whether people prefer Friday to Sunday because of the Weber law. Moreover, a negative time preference implies that the value of a sequence of outcomes does not equal the sum of the values of its parts, and thus, there is no additivity (Loewenstein and Prelec, 1993). Interestingly, Takahashi (2006) shows that the same Weber law can explain such subadditivity.

Although the proposition that Friday is better than Sunday has been aired informally, Farber (1953) is the only study addressing this issue. Farber asked 80 college students to rank the days of the week in order of preference and indicate how they felt about each day. He recruited 28 respondents who had university classes on Saturday, while the remainder did not. Farber finds a rank order similar to the one found in a pioneer study by Cason (1931). Cason asked his students to rate on an 11-point scale how they felt on the different days of the week and discovered that Saturday is the favorite day while Monday is the least favorite (Cason did not care specifically about Friday). Farber explains that "Friday may be pleasantly toned because one anticipates a weekend of leisure," which is a statement compatible with the joy of anticipation hypothesis. However, Farber leans to a rationale based on the psychoanalytic literature that refers to a "Sunday neurosis." Neither Farber nor Cason even mentions the Weber law.

Here, we contribute to the literature by explicitly evaluating whether the fundamental law of psychophysics - the Weber law - provides a better explanation than the joy of anticipation hypothesis. The Weber-Fechner-Stevens law describes the operating characteristic of a sensory system: the perceived difference in a stimulus is proportional to the value of the trigger. Weber and Fechner thought this proportion was logarithm, but Stevens argued for a power law (Stevens, 1961, Bruss and Rueschendorf, 2010). We say that a prediction from the Weber law is that Friday is better than Sunday because people perceive a relative decrease of interesting new events as the weekend passes, which contributes to the feeling that time thins out as Sunday comes.

If the Weber law is at play for many pairs of alternatives, utility functions do not seem to assign unambiguous preference ratings. Moreover, the difficulty increases when the other options differ across dimensions that are difficult to compare. How significant should a stimulus change be so that we can see the difference in its intensity, for instance, in distinguishing a $100 \mathrm{w}$ bulb from a $100.5 \mathrm{w}$ bulb? The minimally noticeable difference is proportional to the original stimulus intensity. The more intense the stimulus to be perceived, the greater the difference needs to be. Consider the perception of price differences. The Weber law is at work when a consumer decides whether to be concerned about them. Kim will buy a wristwatch for $\$ 25$ when Khloe says she saw the same watch for $\$ 20$ at another store 10 minutes away. Will Kim go to the other store? If she is like most consumers, she will. However, if prices were $\$ 1,050$ and $\$ 1,045$, she would not go (Thaler, 1980).

In sum, before settling for the joy of anticipation hypothesis, one may conceivably ask if the fundamental law of psychophysics justifies that people prefer Friday to Sunday. 
We address this task in this paper. A critical caveat is that when testing hypotheses by survey evidence, we should not ignore that people make judgments by memory using their "remembering self," and this is biased; the "experiencing self" is more reliable (Kahneman, 2011; Campara et al., 2021). In particular, judgments based on the experiencing self are superior to deciding between the competing explanations above. We expect unbiased judgments only when people are rating Friday and Sunday on these very days.

\section{Materials and methods}

We sent a questionnaire through social media to our acquaintances working on financial services companies located in Florianopolis, Brazil, who resent it to their acquaintances. We expect a selection bias from this convenience sampling method, but it is not a great deal because our acquaintances' acquaintances make the sample increasingly random. We asked one participant's age and whether he or she was born male or female, in addition to the core questionnaire as follows.

Questionnaire

1. What day of the week are you taking this questionnaire?

( ) Sunday ( ) Monday ( ) Tuesday ( ) Wednesday ( ) Thursday ( ) Friday ( ) Saturday

2. Place the order $(1,2,3,4, \ldots)$ according to your preference for the days of the week.

( ) Sunday ( ) Monday ( ) Tuesday ( ) Wednesday ( ) Thursday ( ) Friday ( ) Saturday

3. How much would you pay today to anticipate the next Friday?

( ) Nothing ( ) Some positive amount less than $\$ 50$ ( ) More than $\$ 50$

4. How much would you pay today to anticipate the next Sunday?

( ) Nothing ( ) Some positive amount less than \$50 ( ) More than $\$ 50$

The first question filters the answers given on Fridays and Sundays from the rest. We expect more reliable answers from Fridays and Sundays because the experiencing self gives these.

Question 2 assesses whether most participants really prefer Friday to Sunday. Again, responses are more reliable if given during these days, but we still want to know whether answers on the other days of the week distort this judgment based on memory. So, we wish to test:

Hypothesis 1a. Participants prefer Friday to Sunday when answering on these days.

Hypothesis 1b. Participants prefer Friday to Sunday when answering on working days.

Questions 3 and 4 aim to confront the joy of anticipation hypothesis vs. the Weber law. Again, we expect more reliable answers from those judging on Fridays and Sundays. If one respondent is willing to spend no cash to anticipate the following Friday, she wants to live up to that expectation following the joy of anticipation hypothesis. Otherwise, there is room for an explanation based on the Weber law. Of particular interest is to compare those who want to spend some cash and answer on Fridays and Sundays with those who spend money and answer on working days. (We leave Saturday out.) So, we assess the validity of the joy of anticipation hypothesis by: 
Hypothesis 2a. Participants do not want to spend any cash to anticipate the following Friday or Sunday when responding on Fridays or Sundays.

Hypothesis 2b. Participants do not want to spend any cash to anticipate the following Friday or Sunday when responding on working days.

\section{Results}

We received 244 valid responses from the participants (ages 25 and older, 72 percent; females, 48 percent). Table 1 shows the days we collected the answers.

Table 1. The day that participants answered the questionnaire.

\begin{tabular}{ll}
\hline Day & $\%$ \\
\hline Saturday & 8.20 \\
Friday & 18.85 \\
Sunday & 9.02 \\
Thursday & 36.07 \\
Wednesday & 9.02 \\
Tuesday & 6.97 \\
Monday & 11.89 \\
\hline
\end{tabular}

Table 2 shows the participants' preference orderings for the days of the week. As expected, they ranked Saturday first but also ranked Friday above Sunday. So people do prefer Friday to Sunday in our sample. This result appears regardless of gender, but younger participants even prefer Friday to Saturday! (Of course, one should take this finding lightheartedly because the difference of the means 2.46 and 2.51 is unlikely to be statistically significant.) Judgments by memory do not distort the preferences of Friday over Sunday because these appear irrespective of the day of the week (last two columns). (Incidentally, the results in our sample justify the belief that people hate Monday.) The scores are significantly distinct across the days of the week in Table 2. For all columns, the Kruskal-Wallis rank-sum test resulted in $p$-values below 0.00001 . Therefore, we could not reject Hypotheses 1a and 1b. Strikingly, the preference orderings in Table 2 exactly match those found by Farber (1953) for students having no Saturday classes, as well as the rankings of Cason (1931).

Table 2. Preference orderings of the days of the week.

\begin{tabular}{|c|c|c|c|c|c|c|c|}
\hline Day & $\begin{array}{l}\text { Overall } \\
\text { mean } \\
(n=244)\end{array}$ & $\begin{array}{l}\text { Female } \\
(n=117)\end{array}$ & $\begin{array}{l}\text { Male } \\
(n=127)\end{array}$ & $\begin{array}{l}\text { Ages }<25 \\
(n=70)\end{array}$ & $\begin{array}{l}\text { Ages } \geq 25 \\
(n=174)\end{array}$ & $\begin{array}{l}\text { Answering } \\
\text { on Fridays } \\
\text { and Sundays } \\
(n=68)\end{array}$ & $\begin{array}{l}\text { Answering } \\
\text { on working } \\
\text { days } \\
(n=156)\end{array}$ \\
\hline Saturday & 2.43 & 2.45 & 2.41 & 2.51 & 2.39 & 2.46 & 2.42 \\
\hline Friday & 2.70 & 2.64 & 2.75 & 2.46 & 2.79 & 2.79 & 2.73 \\
\hline Sunday & 3.56 & 3.69 & 3.43 & 3.61 & 3.53 & 3.29 & 3.58 \\
\hline Thursday & 4.32 & 4.38 & 4.27 & 4.16 & 4.39 & 4.48 & 4.23 \\
\hline Wednesday & 4.89 & 4.99 & 4.79 & 4.85 & 4.90 & 4.88 & 4.86 \\
\hline Tuesday & 4.98 & 4.82 & 5.13 & 5.03 & 4.96 & 4.90 & 5.04 \\
\hline Monday & 5.12 & 5.02 & 5.21 & 5.37 & 5.02 & 5.19 & 5.13 \\
\hline
\end{tabular}

Tables 3 and 4 suggest we cannot reject our hypotheses $2 \mathrm{a}$ and $2 \mathrm{~b}$. Most participants do not want to spend any money to anticipate either the following Friday or Sunday. Comparing those who want to spend nothing (86.07\%) with those who want to spend some amount $(8.2 \%+5.74 \%)$ to anticipate the following Friday, the difference is statistically significant against the hypothesis of uniformity (fifty-fifty), that is, $\chi^{2}=$ 126.95 , $\mathrm{df}=1, p$-value $<2.2 \mathrm{e}-16$ (two-sample test for equality of proportions with continuity correction). And comparing those who do not want to spend (95.49\%) with 
those who do $(3.28 \%+1.23 \%)$ to anticipate the next Sunday, the difference is also statistically significant $\left(\chi^{2}=201.98, \mathrm{df}=1, p\right.$-value $\left.<2.2 \mathrm{e}-16\right)$. Finally, the frequencies in Tables 3 and 4 are statistically distinct. Indeed, after comparing matrix [86.07, $(8.2+$ 5.74)] with matrix [95.49, $(3.28+1.23)]$, we find $\chi^{2}=11.848, \mathrm{df}=1, p$-value $=0.00058$ (two-sample Pearson's chi-squared test with Yates' continuity correction).

This finding holds even if we consider age and gender and whether the experiencing self or memory provides the answers. Moreover, we can see that $14 \%$ of the participants would spend some cash to anticipate the following Friday, and only $4.5 \%$ would pay to anticipate the following Sunday. So, those participants, perhaps judging under the Weber law, would pay three times more to anticipate the next Friday than the following Sunday, thus reinforcing that they also value Friday above Sunday.

Table 3. Willingness to pay to anticipate the following Friday.

\begin{tabular}{|c|c|c|c|c|c|c|c|}
\hline$\$$ & $\begin{array}{l}\text { Overall } \\
\text { sample, \% } \\
(n=244)\end{array}$ & $\begin{array}{l}\text { Female, } \% \\
(n=117)\end{array}$ & $\begin{array}{l}\text { Male, } \% \\
(n=127)\end{array}$ & $\begin{array}{l}\text { Ages <25, } \\
\% \\
(n=70)\end{array}$ & $\begin{array}{l}\text { Ages } \geq 25, \\
\% \\
(n=174)\end{array}$ & $\begin{array}{l}\text { Answering } \\
\text { on Fridays } \\
\text { and } \\
\text { Sundays, \% } \\
(n=68)\end{array}$ & $\begin{array}{l}\text { Answering } \\
\text { on working } \\
\text { days, \% } \\
(n=156)\end{array}$ \\
\hline 0 & 86.07 & 90.60 & 81.89 & 87.14 & 85.63 & 80.88 & 87.82 \\
\hline$<50$ & 8.2 & 3.42 & 12.60 & 7.14 & 8.62 & 8.82 & 8.33 \\
\hline$>50$ & 5.74 & 5.98 & 5.51 & 5.71 & 5.75 & 10.29 & 3.85 \\
\hline
\end{tabular}

Table 4. Willingness to pay to anticipate the following Sunday.

\begin{tabular}{|c|c|c|c|c|c|c|c|}
\hline$\$$ & $\begin{array}{l}\text { Overall } \\
\text { sample, \% } \\
(n=244)\end{array}$ & $\begin{array}{l}\text { Female, } \% \\
(n=117)\end{array}$ & $\begin{array}{l}\text { Male, } \% \\
(n=127)\end{array}$ & $\begin{array}{l}\text { Ages <25, } \\
\% \\
(n=70)\end{array}$ & $\begin{array}{l}\text { Ages } \geq 25, \\
\% \\
(n=174)\end{array}$ & $\begin{array}{l}\text { Answering } \\
\text { on Fridays } \\
\text { and } \\
\text { Sundays, \% } \\
(n=68)\end{array}$ & $\begin{array}{l}\text { Answering } \\
\text { on working } \\
\text { days, \% } \\
(n=156)\end{array}$ \\
\hline 0 & 95.49 & 95.73 & 95.28 & 95.71 & 95.40 & 92.65 & 96.15 \\
\hline$<50$ & 3.28 & 1.71 & 0.79 & 4.29 & 2.87 & 5.88 & 2.56 \\
\hline$>50$ & 1.23 & 2.56 & 3.94 & 0.00 & 1.72 & 1.47 & 1.28 \\
\hline
\end{tabular}

\section{Conclusion}

We provide survey evidence that people prefer Friday to Sunday. But, then, we pit against two explanations for these preferences, the joy of anticipation hypothesis and the perhaps more obvious Weber law. According to the first hypothesis, Friday promises a weekend ahead, and Sunday does not carry the joy of anticipation. In turn, the Weber law implies that people perceive a relative decrease of interesting new events as the weekend passes, which contributes to the feeling that time thins out as Sunday comes.

We consider a sample of 244 participants and analyze the answers considering their age and gender. But, more importantly, we attest whether they answer the questionnaire by their experiencing self or memory.

We find the joy of anticipation hypothesis explains that people rate Friday higher than Sunday for most participants. These do not want to spend any money to anticipate the following Friday or Sunday, indicating that they want to live up to that expectation under the joy of anticipation hypothesis. Furthermore, this result is robust to possible memory biases in the answers given.

\section{References}

Bruss, F.T., Rueschendorf, L (2010) On the perception of time, Gerontology 56 (4), 361370. 
Campara, J., Da Costa Jr., N., Matsushita, R., Da Silva, S. (2021) Two selves and two minds in a longitudinal survey of risk attitudes, Journal of Behavioral and Experimental Finance 29 (C) 100444.

https://doi.org/10.1016/j.jbef.2020.100444

Cason, H. (1931) General curves and conditions of feeling, Journal of Applied Psychology 15 (2), 126-148.

https://doi.org/10.1037/h0073836

Farber, M.L. (1953) Time-perspective and feeling-tone: A study in the perception of the days, Journal of Psychology: Interdisciplinary and Applied 35 (2), 253-257. https://doi.org/10.1080/00223980.1953.9712859

Kahneman, D. (2011) Thinking, Fast and Slow. New York: Farrar, Straus and Giroux.

Loewenstein, G. (1987) Anticipation and the valuation of delayed consumption, Economic Journal 97 (387), 666-684.

https://doi.org/10.2307/2232929

Loewenstein, G., Prelec, D. (1991) Negative time preference, American Economic Review 81 (2), 347-352.

https://www.jstor.org/stable/2006883

Loewenstein, G.F., Prelec, D. (1993) Preferences for sequences of outcomes, Psychological Review 100 (1), 91-108.

https://doi.org/10.1037/0033-295X.100.1.91

Sharot, T. (2011) The Optimism Bias: A Tour of the Irrationally Positive Brain. New York: Pantheon Books.

Stevens, S. S. (1961) To honor Fechner and repeal his law, Science 133 (3446), 80-86. https:/doi.org/10.1126/science.133.3446.80

Takahashi, T. (2006) Time-estimation error following Weber-Fechner law may explain subadditive time-discounting, Medical Hypotheses $67 \quad$ (6), 1372-1374. https://doi.org/10.1016/j.mehy.2006.05.056

Thaler, R. (1980) Toward a positive theory of consumer choice, Journal of Economic Behavior \& Organization 1 (1) 39-60.

https://doi.org/10.1016/0167-2681(80)90051-7 